CLINICAL @LERT

\title{
Helping patients to help themselves: the future for management of ulcerative colitis?
}

\section{P Moayyedi}

\begin{abstract}
Guided self management of ulcerative colitis with follow up on request, compared with traditional management, accelerates treatment provision, reduces visits to specialists and general practitioners, and does not increase morbidity
\end{abstract}

I van Illich believes that "the medical establishment has become a major threat to health". ${ }^{1}$ He reasons that the rise of modern medicine has encouraged a culture of dependency on the medical establishment rather than promoting self caring approaches to illness. This extreme viewpoint has a surprising number of supporters, ${ }^{2}$ perhaps because it contains a grain of truth. Clinicians can be paternalistic and often set up services with little regard to patient preferences or whether this is the most cost effective method of delivering health care. ${ }^{3}$ It is therefore refreshing to read the paper by Robinson et al comparing guided self management with usual care for ulcerative colitis (UC) patients in a randomised controlled trial. ${ }^{4}$ Patients were more satisfied with guided self management, and patients with relapses took steroids earlier. There was also a statistically non-significant trend for relapses to be of shorter duration. The results seem compelling, so should there be widespread implementation of this management strategy for UC?

This was a well designed and clearly reported study but inevitably some questions remain. More than $80 \%$ of participants had distal UC and only 5\% were receiving azathioprine, hence the results pertain mainly to patients with left sided disease not taking long term immunosuppression. There also needs to be longer follow up as the initial enthusiasm for guided self care may diminish with time. There is therefore the danger that patients will be left without specialist input in the long term. Robinson et al will continue to monitor the new system and these results will be important.

The authors highlight the trend towards a reduction in the length of relapses in those allocated to guided self management but are rightly cautious in interpreting this finding. There was also a trend towards a greater proportion of self managed patients to relapse $(61 \%$ in the guided self management arm compared with $49 \%$ in the usual care group). This was not statistically significant and may reflect the fact that relapses were self reported. However, if there were a

\section{Robinson A, Thompson DG, Wilkin D, et al. Guided self-management and patient-directed follow-up of ulcerative colitis: a randomised trial. Lancet $2001 ; 358: 976-81$.}

Background: The traditional pattern of outpatient care for ulcerative colitis in the UK involves regular prearranged hospital visits. Criticisms of this approach are that visits do not coincide with relapses, treatment for relapse is often delayed, for patients hospital visits are inconvenient and often unnecessary, and it is costly for them.

Question: How does guided self management with follow up on request compare with traditional management in terms of speed of relapse treatment, number of consultations, quality of life, and acceptability?

Design: Randomised controlled trial in four hospitals around Manchester, UK. Intervention: A personalised self management regimen was developed during a 15-30 minute consultation with the patient's usual clinician.

Patients: A total of 203 patients, aged more than 16 years, with ulcerative colitis $(84 \%$ left sided disease only) for a median of nine years, with $87 \%$ taking mesalazine maintenance.

Results: Two thirds of patients eligible were randomised. Intervention patients $(n=101)$ had relapses treated within a mean of 15 hours compared with 50 hours in controls (difference 35 hours (95\% confidence interval 16-60)). Intervention patients made fewer visits to hospital $(0.9$ per patient per year $v 2.9$ in controls (difference 2.0, 1.6-2.7)) and to their general practitioner $(0.3 \vee 0.9$ per patient per year; $p<0.006$ ). Only two patients in the intervention group preferred traditional management; $82 \%$ preferred self management. Health related quality of life scores were similar in the two groups and did not change during the trial. Conclusion: Guided self management of ulcerative colitis accelerates treatment provision, reduces visits to specialists and general practitioners, and does not increase morbidity.

$12 \%$ difference in relapse rates this would be clinically important.

What is clear from the data is that UC patients are dissatisfied with the current system, with a staggering $94 \%(80 / 85)$ of those randomised to usual management preferring another approach. It is interesting that although a large number of patients in the self management group preferred this strategy, the proportion was significantly less than those allocated to usual care $(82 \%(71 / 86)$; relative risk 0.88 (95\% confidence interval 0.79 $0.98) ; \mathrm{p}=0.03)$. One interpretation of this result is that patients dislike the current system, and although they prefer the alternative it is not quite as good as they hoped. There may be an overestimation of the satisfaction with guided self management as neither the patients nor the investigators were blinded to the allocation group and this could have biased the results.

The paper highlighted individual cost items such as travel and number of clinic visits that were significantly less in the guided self management group. There were no data on overall cost either from a societal or NHS perspective, however, so it is difficult to establish which approach is more cost effective.

Despite these reservations this is an important study that highlights the deficiencies in the current system for managing UC. The alternative they propose is consistent with the current trend for patients to become more actively involved in their own care. ${ }^{5}$ The approach is also in keeping with the drive to teach medical students with problem based self directed learning. ${ }^{6}$ The evidence will be enough to convince some clinicians to 
adopt guided self management for patients with left sided colitis in remission and without the need for immunosuppression. Others may be more cautious and want further trials from other centres, and comparisons with other strategies such as nurse led clinics and telephone consultations. ${ }^{78}$

Gut 2002;51:309-310

\section{Author's affiliation}

P Moayyedi, Gastroenterology Unit, City Hospital NHS Trust, Dudley Rd, Birmingham B18 7QH, UK; p.moayyedi@bham.ac.uk

\section{REFERENCES}

1 Illich I. Limits to medicine. Medical nemesis: the expropriation of health. London: Penguin Books, 1990.

2 Edwards RH. Is it time for an Illich collaboration to make available information on the harms of medical care? BM 1999;318:58.

3 Moayyedi $\mathbf{P}$, Wardman $M$, Toner J, et al. Establishing patient preferences for gastroenterology clinic re-organisation using conjoint analysis. Eur J Gastroenterol Hepatol 2002; 14:429-33.

4 Robinson A, Thompson DG, Wilkin D, et al. Guided self-management and patient-directed follow-up of ulcerative colitis: a randomised trial. Lancet 2001;358:976-81.
5 Troop N, Treasure J, Schmidt U. From specialist care to self directed treatment. BM 1993:307:577-8.

6 Shin JH, Haynes RB, Johnston ME. Effect of problem-based, self-directed undergraduate education on life-long learning. Can Med Assoc J 1993;148:969-76.

7 Nightingale AJ, Middleton W, Middleton SJ, et al. Evaluation of the effectiveness of a specialist nurse in the management of inflammatory bowel disease. Eur J

Gastroenterol Hepatol 2000;12: 967-73.

8 Wasson J, Gaudette C, Whaley F, et al. Welch HG. Telephone care as a substitute for routine clinic follow-up. JAMA 1992:267:1788-93.

\section{Clinical Evidence-Call for contributors}

Clinical Evidence is a regularly updated evidence based journal available world wide both as a paper version and on the internet. Clinical Evidence urgently needs to recruit a number of new contributors. Contributors are health care professionals or epidemiologists with experience in evidence based medicine and the ability to write in a concise and structured way.

We are presently interested in finding contributors with an interest in the following clinical areas:

$\begin{array}{ll}\text { Angina pectoris } & \text { Hepatitis C } \\ \text { Attention deficit hyperactivity disorder } & \text { HIV } \\ \text { Genital warts } & \text { Influenza } \\ \text { Hepatitis B } & \text { Varicose veins }\end{array}$

Being a contributor involves:

- Appraising the results of literature searches (performed by our Information Specialists) to identify high quality evidence for inclusion in the journal.

- Writing to a highly structured template (about 1500-3000) words), using evidence from selected studies, within 6-8 weeks of receiving the literature search results.

- Working with Clinical Evidence Editors to ensure that the text meets rigorous epidemiological and style standards.

- Updating the text every eight months to incorporate new evidence.

- Expanding the topic to include new questions once every eight months to incorporate new evidence.

- Expanding the topic to include new questions once every 12-18 months.

If you would like to become a contributor for Clinical Evidence or require more information about what this involves, please send your contact details and a copy of your $\mathrm{CV}$, clearly stating the clinical area you are interested in, to Polly Brown (pbrown@bmigroup.com). 